\title{
Berberine in combination with cisplatin suppresses breast cancer cell growth through induction of DNA breaks and caspase-3-dependent apoptosis
}

\author{
YUWAN ZHAO $^{1}$, ZUOLEI JING $^{2}$, YAN LI $^{3}$ and WEIFENG MAO ${ }^{1}$ \\ ${ }^{1}$ Department of Biotechnology, College of Basic Medical Sciences, Dalian Medical University; \\ ${ }^{2}$ Institute of Gene Engineering Animal Models for Human Diseases, Dalian Medical University; ${ }^{3}$ Department of \\ Anatomy, College of Basic Medical Sciences, Dalian Medical University, Dalian, Liaoning 116044, P.R. China
}

Received December 15, 2015; Accepted February 26, 2016

DOI: $10.3892 /$ or.2016.4785

\begin{abstract}
Berberine (BBR) is an isoquinoline alkaloid extracted from medicinal plants such as Hydrastis canadensis, Berberis aristata and Coptis chinensis. BBR displays a number of beneficial roles in the treatment of various types of cancers, yet the precise mechanisms of its action remain unclear. Cisplatin is an effective cancer chemotherapeutic agent and functions by generating DNA damage, promoting DNA damage-induced cell cycle arrest and apoptosis; however, its efficacy is challenged by the resistance of tumor cells in clinical application. The aim of the present study was to investigate the effects of BBR in combination with cisplatin on human breast cancer cells. MTT assay showed that BBR inhibited breast cancer MCF-7 cell growth with a 50\% inhibitory concentration $\left(\mathrm{IC}_{50}\right)$ value of $52.178 \pm 1.593 \mu \mathrm{M}$ and the $\mathrm{IC}_{50}$ value of cisplatin was $49.541 \pm 1.618 \mu \mathrm{M}$, while in combination with $26 \mu \mathrm{M} \mathrm{BBR}$, the $\mathrm{IC}_{50}$ value of cisplatin was $5.759 \pm 0.76 \mu \mathrm{M}$. BBR sensitized the MCF-7 cells to cisplatin in a time- and dose-dependent manner. After treatment of BBR and cisplatin, the cellular pro-apoptotic capase- 3 and cleaved capspase- 3 and caspase- 9 were upregulated and the anti-apoptotic Bcl-2 was downregulated. Importantly, BBR restrained the expression of cellular PCNA, and immunofluoresence analysis of $\gamma \mathrm{H} 2 \mathrm{AX}$ showed that BBR increased the DNA damages induced by cisplatin. Taken together, the results demonstrated that BBR sensitized
\end{abstract}

Correspondence to: Dr Weifeng Mao, Department of Biotechnology, College of Basic Medical Sciences, Dalian Medical University, Dalian, Liaoning 116044, P.R. China

E-mail: maoweifeng@dlmedu.edu.cn

Dr Yan Li, Department of Anatomy, College of Basic Medical Sciences, Dalian Medical University, Dalian, Liaoning 116044, P.R. China

E-mail: 1y316@126.com

Key words: berberine, cisplatin, breast cancer, apoptosis, DNA damage
MCF-7 cells to cisplatin through induction of DNA breaks and caspase-3-dependent apoptosis.

\section{Introduction}

Breast cancer is one of the most common malignancies among women, with 458,000 annual deaths worldwide $(1,2)$. Treatment strategies for breast cancer include surgery, radiotherapy, hormone therapy, chemotherapy or a combination of these methods (3). A range of chemotherapeutic drugs are employed in the treatment of breast cancer, in which platinum agents represent a class of common chemotherapeutic drugs, such as cisplatin or carboplatin (4). Cisplatin is currently the most effective chemotherapeutic drug used to treat breast cancer. Cisplatin is a genotoxic agent and the mechanism of action includes induction of DNA damages; therefore it is considered to be dose-limiting (6). The efficacy of this chemotherapeutic agent is often low due to adverse side effects and drug resistance (7-10). High resistance to cisplatin is a major challenge in the successful treatment of breast cancer, and there is currently no effective cure for patients with advanced stage of the disease. Consequently, strategies designed to sensitize breast cancer cells to cisplatin are still under investigation.

Berberine (BBR) is an isoquinoline alkaloid extracted from the rhizomes of a variety of valuable medicinal plants, including Coptis chinensis and Coptis japonica (11). BBR has been reported to possess a wide variety of pharmacological activities as an anti-microbial and anti-inflammatory agent (12-15). Currently, the anticancer activities of BBR have been reported in a range of cancers including hepatoma, prostate cancer, glioblastoma, ovarian cancer, leukemia and breast cancer (16-24). BBR achieves its antitumor effect through inhibition of cell proliferation and induction of tumor cell apoptosis although the underlying molecular mechanisms of BBR involved in the inhibition of cancer cell growth have not been fully elucidated (25-29). BBR has been demonstrated to directly bind with DNA and interfere with DNA replication as a DNA topoisomerase I inhibitor, through which BBR eventually induces cellular apoptosis. Studies have also shown that BBR binds to DNA, and radiosensitized lung cancer and esophageal cancer cells by regulating 
the expression of DNA repair-associated proteins (30-33), and BBR was found to modulate the anticancer effects of doxorubicin and rapamycin in human cancer cells $(34,35)$. Although the mechanisms through which BBR sensitizes cancer cells to radiation or chemotherapy agents remain unclear, it is likely that BBR increases DNA damage induced by various therapeutic drugs.

As resistance to cisplatin of breast cancer is still a major challenge for the successful treatment of this disease, in the present study, we focused on the effects of BBR on the sensitivity of breast cancer cells to cisplatin and the mechanisms through which BBR functions in breast cancer cells. In combination with cisplatin, a low dose of BBR suppressed the proliferation of MCF-7 cells, increased apoptotic-associated protein expression, and more importantly, BBR increased the DNA breaks induced by cisplatin. In conclusion, our findings demonstrated that BBR increased the genotoxic ability of cisplatin and sensitized breast cancer cells to cisplatin, which could be a potential strategy for the treatment of breast cancer patients with cisplatin resistance.

\section{Materials and methods}

Cell culture. The human breast cancer MCF-7 cell line was obtained from the American Type Culture Collection (ATCC, Manassas, VA, USA). The cells were cultured in RPMI-1640 culture medium supplemented with $10 \%$ heat-inactivated fetal bovine serum (FBS) (both from Hyclone, Waltham, MA, USA), $100 \mathrm{U} / \mathrm{ml}$ penicillin and $100 \mathrm{mg} / \mathrm{ml}$ streptomycin (Thermo Fisher Scientific, Waltham, MA, USA).

Antibodies and reagents. Berberine (BBR), cisplatin and DMSO were purchased from Sigma (St. Louis, MO, USA). Antibodies to GAPDH were purchased from ProteinTech Group, Inc. (Chicago, IL, USA) and the antibody to $\gamma \mathrm{H} 2 \mathrm{AX}$ was obtained from CST (Boston, MA, USA).

Cell viability assay. Cell viability was determined by the MTT assay. Briefly, breast cancer cells were seeded at $4 \times 10^{3}$ cells/well in 96-well plates overnight, cultured in fresh medium containing various concentrations of BBR and cisplatin was dissolved in DMSO. After incubation for $44 \mathrm{~h}$, MTT $(0.5 \mathrm{mg} / \mathrm{ml}$; Sigma-Aldrich) was added and $4 \mathrm{~h}$ later the growth of the cells was measured at $492 \mathrm{~nm}$ using a microplate photometer (Thermo Fisher Scientific). The effect of the drugs on cell viability was assessed as the percentages of cell viability compared with the control cells which were arbitrarily assigned as having $100 \%$ viability.

Wound-healing assay. The cells were grown to full confluency in 6-well plates and incubated overnight. Cell monolayers were wounded with a sterile $10-\mu l$ pipette tip, washed with PBS, and treated with the indicated dose of BBR $(13 \mu \mathrm{M})$ or cisplatin $(3.3 \mu \mathrm{M})$ or the combination in complete medium. After a 48-h incubation, the medium was replaced with PBS, and the wound gap was observed and photographed using an Olympus microscope (Olympus, Tokyo, Japan).

Anchorage-independent colony formation assay. MCF-7 cells were treated with BBR $(13 \mu \mathrm{M})$ and cisplatin $(3.3 \mu \mathrm{M})$ for
$48 \mathrm{~h}$. The cells were washed with PBS and trypsinized with trypsin ( $0.25 \%$ trypsin, EDTA) and 400 cells were seeded into a well of the 6 -well plates. The cultures were maintained in an incubator at $37^{\circ} \mathrm{C}$ with $5 \% \mathrm{CO}_{2}$ for 10 days. The cells were washed with PBS twice, fixed with methanol for $15 \mathrm{~min}$, stained with Giemsa for 15 min, washed with water and airdried. The colonies with more than 50 cells were counted under an ordinary optical microscope.

Western blot analysis. After incubation with $13 \mu \mathrm{M}$ BBR and $3.3 \mu \mathrm{M}$ cisplatin for $48 \mathrm{~h}$, the cells were lysed in RIPA lysis buffer. Whole cell proteins were quantified using the BCA protein assay (KangChen Bio-tech, Shanghai, China), separated by electrophoresis using $10 \%$ SDS-PAGE and transferred to a PVDF membrane. Western blot analyses were probed with the specific antibodies at dilution conditions as follows: mouse anti-GAPDH $(1: 4,000), \beta$-actin $(1: 4,000)$, caspase- 9 (1:500), rabbit anti-caspase-3 (1:500), Bcl2 (1:500), anti-mouse and rabbit $\operatorname{IgG}(\mathrm{H}+\mathrm{L})$ secondary antibodies $(1: 5,000)$; all the antibody were purchased from ProteinTech Group, Inc.

Immunofluorescence analysis. Cells grown on chamber slides were treated with BBR $(13 \mu \mathrm{M})$ in combination with cisplatin $(3.3 \mu \mathrm{M})$. After $48 \mathrm{~h}$, the cells were washed with PBS and then fixed with $4 \%$ paraformaldehyde at room temperature for $30 \mathrm{~min}$, and then washed with PBS for three times. After permeabilization in $0.2 \%$ Triton X-100 for $30 \mathrm{~min}$, the cells were washed twice in PBS and blocked for $1 \mathrm{~h}$ in PBS containing 1\% BSA (all from Solarbio, Beijing, China). The cell pellet was suspended in $100 \mu \mathrm{l}$ of $1 \%$ BSA containing either 1:100 diluted anti- $\gamma \mathrm{H} 2 \mathrm{AX}$ polyclonal Ab (CST). The cells were then incubated overnight at $4^{\circ} \mathrm{C}$. On the following day, the cells were washed twice with PBS and incubated in $100 \mu 1$ of 1:100 diluted Alexa Fluor 488-conjugated anti-rabbit $\operatorname{IgG}$ (Thermo Fischer Scientific) for $2 \mathrm{~h}$ at room temperature in the dark. After washing with PBS three times, the cells were dyed with Hoechst 33342 (Sigma, St. Louis, MO, USA) for $3 \mathrm{~min}$, and washed with PBS for three times, and then photographed under a microscope (Olympus).

Statistical analysis. Data analysis was carried out using SPSS 6.0 software. One-way ANOVA was used to determine the significance of the differences in multiple comparisons; $\mathrm{p}<0.05, \mathrm{p}<0.01, \mathrm{p}<0.001, \mathrm{p}<0.0001$ were considered statistically significant. All experiments were performed in triplicate. Data are expressed as the mean \pm SD. We used Image J and IPP6.0 software to process and analysis the immunofluorescence image.

\section{Results}

Berberine in combination with cisplatin suppresses MCF-7 cell proliferation. We analyzed the effect of BBR in combination with cisplatin on human breast cancer MCF-7 cell proliferation by MTT assay. After a 48-h BBR treatment, the $\mathrm{IC}_{50}$ value of BBR in the MCF-7 cells was $52.178 \pm 1.593 \mu \mathrm{M}$ and the $\mathrm{IC}_{50}$ value of cisplatin was $49.541 \pm 1.618 \mu \mathrm{M}$. In contrast, following combination with $26 \mu \mathrm{M}$ BBR, the $\mathrm{IC}_{50}$ value of cisplatin was $5.759 \pm 0.76 \mu \mathrm{M}$ (Fig. 1A). BBR increased the sensitivity of MCF-7 cells to cisplatin in a dose and time-dependent manner (Fig. 1A and B). 

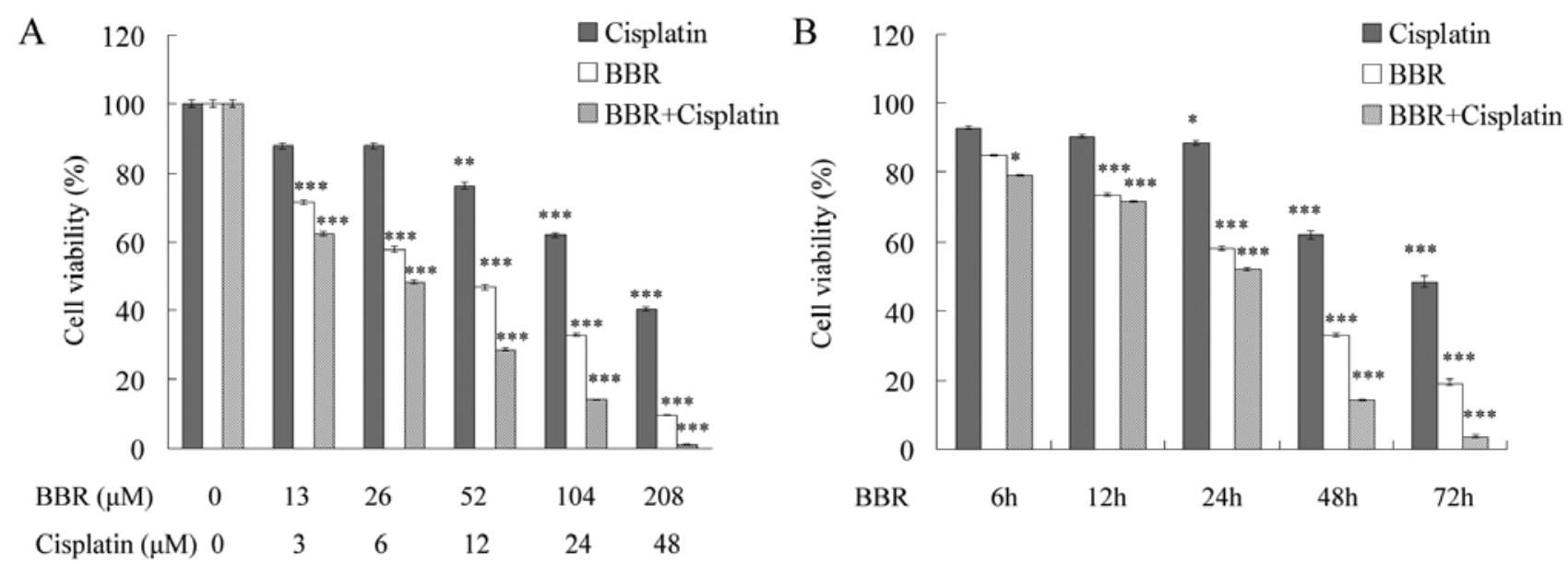

Figure 1. Berberine in combination with cisplatin suppress MCF-7 cell proliferation. Human breast cancer MCF-7 cells were treated with BBR and cisplatin at the indicated doses. After a 48-h treatment, the cell viability was assessed by MTT assay, and the $\mathrm{IC}_{50}$ values of BBR and cisplatin in the MCF-7 cells were calculated. (A) BBR and cisplatin inhibited cell viability in a dose-dependent manner. (B) BBR and cisplatin inhibited cell viability in a time-dependent manner. Cells treated with DMSO were used as the control group with cell viability set at $100 \%$. The percent cell viability in each treatment group was calculated relative to the cells treated with the DMSO control. Data are presented as the mean \pm SD of three tests. ${ }^{*} \mathrm{p}<0.05,{ }^{* *} \mathrm{p}<0.01,{ }^{* * *} \mathrm{p}<0.001$ indicate significant differences between the treatment and DMSO control group.
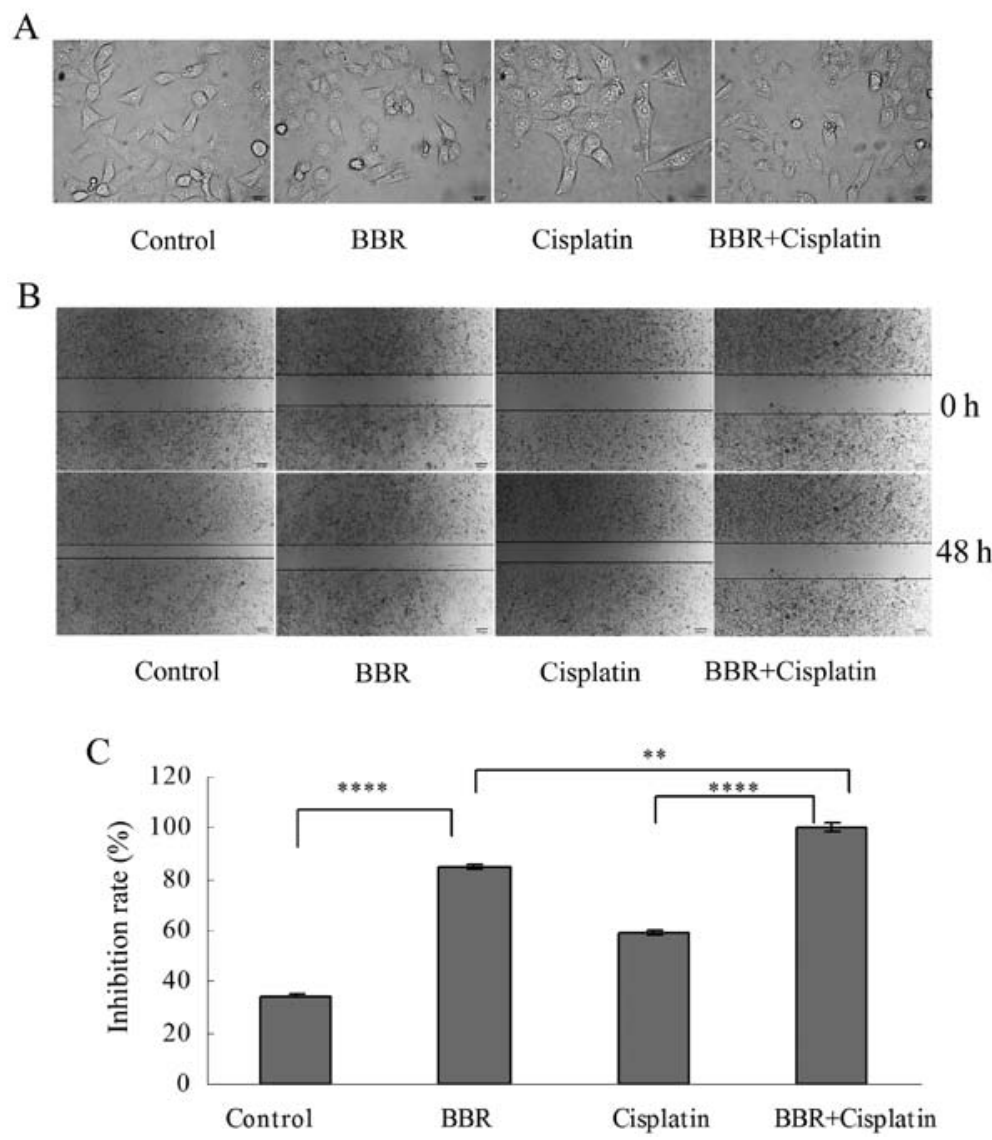

Figure 2. Berberine, cisplatin and the combination of the two drugs alter cell morphology and inhibit migration. (A) Changes in the morphology of the MCF-7 cells treated with BBR and cisplatin were observed. Cell migration was analyzed by a wound healing assay. (B and C) The wound gap was observed and cells were photographed. Cells treated with DMSO were used as control. The percentage of inhibition in each treatment group was calculated relative to cells treated with BBR and cisplatin. The data are presented as mean $\pm \mathrm{SD}$ of three tests. ${ }^{* *} \mathrm{p}<0.01,{ }^{* * * *} \mathrm{p}<0.0001$ indicate significant differences between the treatment and DMSO control group.

Berberine modifies cell morphology and inhibits cell migration and colony formation. Following treatment of the MCF-7 cells with BBR at the dose of $13 \mu \mathrm{M}$ and with cisplatin at $3.3 \mu \mathrm{M}$, reduced cell-cell contact and the formation of filopodia were observed (Fig. 2A). The wound healing assay showed that BBR and cisplatin inhibited the migration of MCF-7 cells. BBR in combination with cisplatin further inhibited the migration of MCF-7 cells (Fig. 2B and C). Each drug administered 

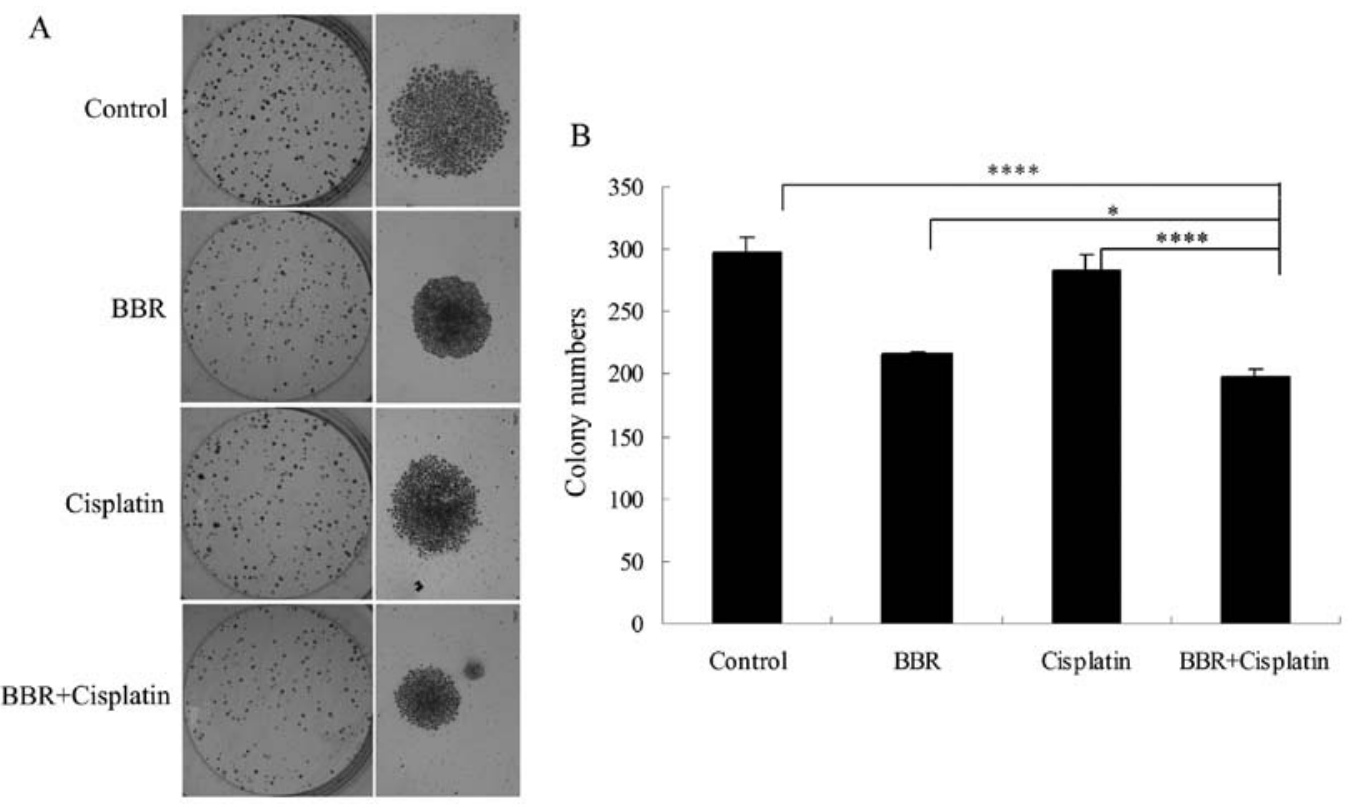

Figure 3. Berberine, cisplatin and the combination of the two drugs suppress cell colony formation. Cells were either untreated or treated with BBR and cisplatin. (A and B) Cells (400) were plated in 6-well plates, and 10 days later, the cells were stained and calculated. Cells treated with DMSO were used as control. The colony numbers were calculated. The data are presented as mean $\pm \mathrm{SD}$ of three tests. ${ }^{*} \mathrm{p}<0.05,{ }^{* * * * *} \mathrm{p}<0.0001$ indicate significant differences between the treatment and DMSO control group.
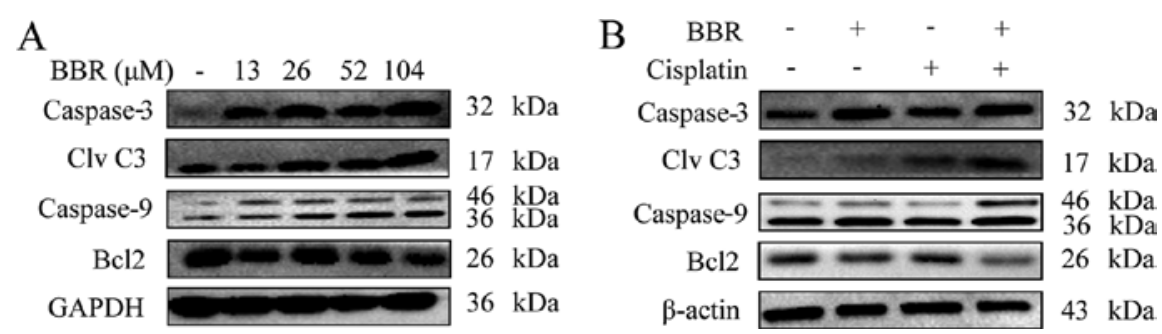

Figure 4. Berberine activates the caspase-dependent apoptotic pathway. (A) Cells were treated with BBR and (B) the combination of BBR and cisplatin; western blot analysis results showed that BBR and the combination of BBR and cisplatin inhibited the expression of Bcl-2, and promoted the cleavage of caspase-3/9.

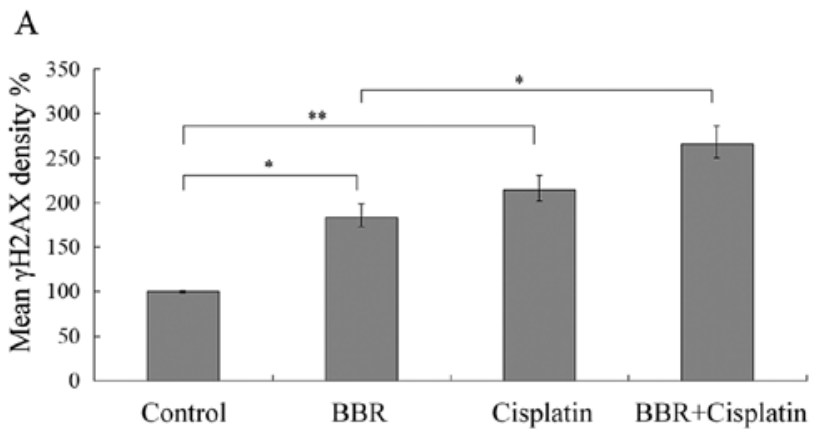

B

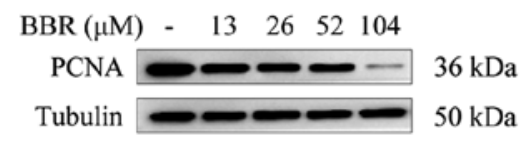

Figure 5. Berberine increases DNA breaks and restrains the expression of PCNA. Immunofluorescence results showed that BBR increased the DNA breaks induced by cisplatin. Cells treated with DMSO were used as control group with mean $\gamma \mathrm{H} 2 \mathrm{AX}$ density set at $100 \%$. (A) The percentage of the mean $\gamma \mathrm{H} 2 \mathrm{AX}$ density in each treatment group was calculated relative to cells treated with DMSO vehicle control. Data are presented as mean \pm SD of three tests. ${ }^{*} \mathrm{p}<0.05,{ }^{* *} \mathrm{p}<0.01$ indicate significant difference between the treatment and DMSO control group. (B) Effect of BBR on expression of cellular PCNA was detected through western blot assay. alone suppressed cell colony formation. BBR in combination with cisplatin further suppressed MCF-7 cell colony formation (Fig. 3A and B).

Berberine sensitizes MCF-7 cells to cisplatin through the caspase-3-dependent apoptotic pathway. We next tested whether BBR and cisplatin induce apoptotic-associated proteins. The expression levels of pro-apoptotic proteins, caspase-3 and caspase- 9 and anti-apoptotic protein $\mathrm{Bcl}-2$ in MCF-7 cells were analyzed by western blot analysis. BBR increased the expression levels of caspase-3 and caspase-9 compared with these levels in the control group (Fig. 4A). A low dose of BBR $(13 \mu \mathrm{M})$ in combination with cisplatin increased the expression of cleaved caspase- 3 and caspase- 9 , but decreased expression of Bcl-2 compared with these levels in the cells treated with cisplatin alone $(3.3 \mu \mathrm{M})$ (Fig. 4B). The results indicate that BBR sensitized MCF-7 breast cancer cells to cisplatin through a caspase-3-dependent apoptotic pathway.

Berberine increases DNA breaks and restrains the expression of PCNA. We used immunofluorescence analysis to test $\gamma \mathrm{H} 2 \mathrm{AX}$ foci in the cells. The cells were cultured with 
BBR and cisplatin for $48 \mathrm{~h}$, and $\gamma \mathrm{H} 2 \mathrm{AX}$ foci are shown in Fig. 5A. The result showed that cisplatin induced DNA breaks, and a low dose of BBR increased the DNA breaks induced by cisplatin. We also detected the effect of BBR on expression of PCNA, an important factor in DNA replication and DNA repair. BBR extensively reduced the expression of PCNA (Fig. 5B), suggesting that BBR may regulate the cellular DNA repair pathway to increase DNA breaks and sensitize cells to cisplatin.

\section{Discussion}

Currently, breast cancer treatment includes surgery, chemotherapy, hormone therapy, radiotherapy, and combinations of these methods. Conventional cisplatin is still the most effective chemotherapeutic agent in breast cancer treatment. However, the resistance of tumor cells to cisplatin is a considerable obstacle to effective breast cancer therapy. Due to the genotoxicity of cisplatin, the drug is often considered to be dose-limiting. Therefore, it would be beneficial for chemotherapeutic treatment if alternative reliable agents can sensitize cancer cells to cisplatin. Berberine is a traditional Chinese medicine and has been demonstrated to function in anticancer therapy with minor side effects. Thus, we evaluated the sensitization of MCF-7 cells to BBR in combination with cisplatin and the mechanisms of BBR action involved in the inhibition of breast cancer cells.

BBR inhibited breast cancer MCF-7 cell growth, and suppressed breast cancer cell colony formation and migration. We investigated the effect of a low level of BBR in combination with cisplatin on apoptosis and DNA breaks. A low level of BBR increased apoptotic caspase-3 and caspase-9 expression, reduced $\mathrm{Bcl} 2$ expression in combination with cisplatin. The results demonstrated that a low level of BBR greatly increased cisplatin-induced caspase- 3 activation although this dose of BBR had a limited effect on the cell proliferation of the MCF-7 cells. To study the mechanism of BBR-induced apoptosis, we investigated the DNA breaks induced by BBR and cisplatin. A low level of BBR had a limited effect on cell growth, however, BBR greatly increased the sensitivity of the cells to genotoxic cisplatin. BBR in combination with cisplatin induced more $\gamma \mathrm{H} 2 \mathrm{AX}$ foci, suggesting that BBR increased the DNA damage induced by cisplatin. The increased cellular DNA damage may result in subsequent apoptosis and suppression of MCF-7 cell proliferation. BBR was reported to bind to DNA directly and to interfere with DNA replication (33), which would be a possible explanation for the ability of BBR to sensitize breast cancer cells to chemotherapeutic cisplatin. To address the role of BBR in regulating cellular DNA repair, we detected the effect of BBR on expression of proliferating cell nuclear antigen (PCNA), a DNA sliding clamp required for DNA pold to replicate DNA and is crucial in DNA repair (36). BBR extensively restrained the expression level of PCNA, suggesting that BBR may decrease the cellular DNA repair ability to sensitize cells to genotoxic cisplatin.

In conclusion, our data demonstrated that BBR suppressed breast cancer MCF-7 cell proliferation, colony formation and migration. A low level of BBR sensitized breast cancer cells to cisplatin, regulated cleaved caspase-3, caspase-9, Bcl-2 protein expression, and more importantly, BBR increased the
DNA damages induced by cisplatin and reduced the cellular PCNA level. These results suggest that a low level of BBR can regulate cellular DNA repair and promote the DNA breaks induced by cisplatin, further potentiating the breast cancer cells to cisplatin-induced apoptosis, which could be one of the mechanisms of BBR action in antitumor activity. Given the wide application of cisplatin and other platinum-based drugs in cancer treatment and the relatively limited side effects of a low dose of BBR, our studies suggest an alternative approach to circumvent the cancer resistance to cisplatin and to improve the efficacy of platinum-based chemotherapeutic treatment. Further studies are needed to determine the clinical relevance of BBR in combination with cisplatin.

\section{Acknowledgements}

We thank the Department of Biotechnology and Cancer and Stem Cell Research Center, Dalian Medical University for technical support. This study is supported by Chinese NSF grant nos. 31371254 and 81201563 .

\section{References}

1. Harris JR, Lippman ME, Veronesi U and Willett W: Breast cancer. N Engl J Med 327: 473-480, 1992.

2. Bray F, Jemal A, Grey N, Ferlay J and Forman D: Global cancer transitions according to the Human Development Index (2008-2030): a population-based study. Lancet Oncol 13: 790-801, 2012.

3. Buzdar AU: Role of biologic therapy and chemotherapy in hormone receptor- and HER2-positive breast cancer. Ann Oncol 20: 993-999, 2009.

4. Cohen SM, Mukerji R, Cai S, Damjanov I, Forrest ML and Cohen MS: Subcutaneous delivery of nanoconjugated doxorubicin and cisplatin for locally advanced breast cancer demonstrates improved efficacy and decreased toxicity at lower doses than standard systemic combination therapy in vivo. Am J Surg 202: 646-652, discussion 652-653, 2011.

5. Fuertes MA, Castilla J, Alonso C and Pérez JM: Cisplatin biochemical mechanism of action: from cytotoxicity to induction of cell death through interconnections between apoptotic and necrotic pathways. Curr Med Chem 10: 257-266, 2003.

6. Leonard BJ, Eccleston E, Jones D, Todd P and Walpole A: Antileukaemic and nephrotoxic properties of platinum compounds. Nature 234: 43-45, 1971.

7. Köberle B, Tomicic MT, Usanova S and Kaina B: Cisplatin resistance: preclinical findings and clinical implications. Biochim Biophys Acta 1806: 172-182, 2010.

8. Galluzzi L, Senovilla L, Vitale I, Michels J, Martins I, Kepp O, Castedo M and Kroemer G: Molecular mechanisms of cisplatin resistance. Oncogene 31: 1869-1883, 2012.

9. Shen DW, Pouliot LM, Hall MD and Gottesman MM: Cisplatin resistance: a cellular self-defense mechanism resulting from multiple epigenetic and genetic changes. Pharmacol Rev 64: 706-721, 2012.

10. Liu FS: Mechanisms of chemotherapeutic drug resistance in cancer therapy-a quick review. Taiwan J Obstet Gynecol 48: 239-244, 2009.

11. Imanshahidi $M$ and Hosseinzadeh $\mathrm{H}$ : Pharmacological and therapeutic effects of Berberis vulgaris and its active constituent, berberine. Phytother Res 22: 999-1012, 2008.

12. Kheir MM, Wang Y, Hua L, Hu J, Li L, Lei F and Du L: Acute toxicity of berberine and its correlation with the blood concentration in mice. Food Chem Toxicol 48: 1105-1110, 2010.

13. Satou T, Akao N, Matsuhashi R, Koike K, Fujita K and Nikaido T: Inhibitory effect of isoquinoline alkaloids on movement of second-stage larvae of Toxocara canis. Biol Pharm Bull 25: 1651-1654, 2002.

14. Kuo CL, Chi CW and Liu TY: The anti-inflammatory potential of berberine in vitro and in vivo. Cancer Lett 203: 127-137, 2004. 
15. Chi L, Peng L, Hu X, Pan N and Zhang Y: Berberine combined with atorvastatin downregulates LOX-1 expression through the ET-1 receptor in monocyte/macrophages. Int J Mol Med 34: 283-290, 2014

16. Zhu Y, Ma N, Li HX, Tian L, Ba YF and Hao B: Berberine induces apoptosis and DNA damage in MG 63 human osteosarcoma cells. Mol Med Rep 10: 1734-1738, 2014.

17. Huang ZH, Zheng HF, Wang WL, Wang Y, Zhong LF, Wu JL and Li QX: Berberine targets epidermal growth factor receptor signaling to suppress prostate cancer proliferation in vitro. Mol Med Rep 11: 2125-2128, 2015

18. Wu K, Yang Q, Mu Y, Zhou L, Liu Y, Zhou Q and He B: Berberine inhibits the proliferation of colon cancer cells by inactivating Wnt/ß-catenin signaling. Int J Oncol 41: 292-298, 2012.

19. Ortiz LM, Lombardi P, Tillhon M and Scovassi AI: Berberine, an epiphany against cancer. Molecules 19: 12349-12367, 2014.

20. Hwang JM, Kuo HC, Tseng TH, Liu JY and Chu CY: Berberine induces apoptosis through a mitochondria/caspases pathway in human hepatoma cells. Arch Toxicol 80: 62-73, 2006.

21. Lin CC, Yang JS, Chen JT, Fan S, Yu FS, Yang JL, Lu CC Kao MC, Huang AC, Lu HF, et al: Berberine induces apoptosis in human HSC-3 oral cancer cells via simultaneous activation of the death receptor-mediated and mitochondrial pathway. Anticancer Res 27: 3371-3378, 2007.

22. Choi MS, Oh JH, Kim SM, Jung HY, Yoo HS, Lee YM, Moon DC Han SB and Hong JT: Berberine inhibits p53-dependent cell growth through induction of apoptosis of prostate cancer cells Int J Oncol 34: 1221-1230, 2009.

23. Kim S, Han J, Kim NY, Lee SK, Cho DH, Choi MY, Kim JS, Kim JH, Choe JH, Nam SJ, et al: Effect of berberine on p53 expression by TPA in breast cancer cells. Oncol Rep 27: 210-215, 2012.

24. Kim JB, Yu JH, Ko E, Lee KW, Song AK, Park SY, Shin I, Han W and Noh DY: The alkaloid Berberine inhibits the growth of Anoikis-resistant MCF-7 and MDA-MB-231 breast cancer cell lines by inducing cell cycle arrest. Phytomedicine 17: 436-440, 2010.

25. Katiyar SK, Meeran SM, Katiyar N and Akhtar S: p53 cooperates berberine-induced growth inhibition and apoptosis of non-small cell human lung cancer cells in vitro and tumor xenograft growth in vivo. Mol Carcinog 48: 24-37, 2009.

26. Tan W, Li Y, Chen M and Wang Y: Berberine hydrochloride: anticancer activity and nanoparticulate delivery system. Int J Nanomedicine 6: 1773-1777, 2011.
27. Kang JX, Liu J, Wang J, He C and Li FP: The extract of Huanglian, a medicinal herb, induces cell growth arrest and apoptosis by upregulation of interferon-beta and TNF-alpha in human breast cancer cells. Carcinogenesis 26: 1934-1939, 2005.

28. Liu J, He C, Zhou K, Wang J and Kang JX: Coptis extracts enhance the anticancer effect of estrogen receptor antagonists on human breast cancer cells. Biochem Biophys Res Commun 378: 174-178, 2009.

29. Tsang CM, Lau EP, Di K, Cheung PY, Hau PM, Ching YP, Wong YC, Cheung AL, Wan TS, Tong Y, et al: Berberine inhibits Rho GTPases and cell migration at low doses but induces G2 arrest and apoptosis at high doses in human cancer cells. Int J Mol Med 24: 131-138, 2009.

30. Singh T, Vaid M, Katiyar N, Sharma S and Katiyar SK: Berberine, an isoquinoline alkaloid, inhibits melanoma cancer cell migration by reducing the expressions of cyclooxygenase-2, prostaglandin $\mathrm{E}_{2}$ and prostaglandin $\mathrm{E}_{2}$ receptors. Carcinogenesis 32: 86-92, 2011.

31. Krey AK and Hahn FE: Berberine: Complex with DNA. Science 166: 755-757, 1969.

32. Peng PL, Kuo WH, Tseng HC and Chou FP: Synergistic tumor-killing effect of radiation and berberine combined treatment in lung cancer: the contribution of autophagic cell death. Int J Radiat Oncol Biol Phys 70: 529-542, 2008.

33. Liu Q, Jiang H, Liu Z, Wang Y, Zhao M, Hao C, Feng S, Guo H, $\mathrm{Xu} \mathrm{B}$, Yang Q, et al: Berberine radiosensitizes human esophageal cancer cells by downregulating homologous recombination repair protein RAD51. PLoS One 6: e23427, 2011.

34. Tong N, Zhang J, Chen Y, Li Z, Luo Y, Zuo H and Zhao X: Berberine sensitizes mutliple human cancer cells to the anticancer effects of doxorubicin in vitro. Oncol Lett 3: 1263-1267, 2012.

35. Guo N, Yan A, Gao X, Chen Y, He X, Hu Z, Mi M, Tang X and Gou X: Berberine sensitizes rapamycin mediated human hepatoma cell death in vitro. Mol Med Rep 10: 3132-3138, 2014.

36. Zhu Q, Chang Y, Yang J and Wei Q: Post-translational modifications of proliferating cell nuclear antigen: a key signal integrator for DNA damage response (Review). Oncol Lett 7: 1363-1369, 2014. 